\title{
Standardization and ten essential steps in the lateral robotic extended totally extraperitoneal (eTEP) repair of ventral hernias
}

\section{Hérnias ventrais por acesso lateral totalmente extraperitoneal robótico (eTEP): dez etapas essenciais na padronização técnica.}

Andre luiz Giola Morrelli,2,3 (iD; AleXander Morrell, TCBC-SP1,2,3; Alexander Charles Morrell-Junior 1,2,3; Jose Mauricio de Freitas Mendes, ACBC-SP1,2,3; Allan Giola MorrelL ${ }^{1,3}$.

\section{A B S T R A C T}

\begin{abstract}
Objectives: described by Dr. Jorge Daes, principles of the enhanced view totally extraperitoneal (eTEP) has been widely used in the armamentarium of ventral hernia repair recently. Robotic assisted eTEP technique feasibility has been proved, however, a complete understanding of retromuscular abdominal wall planes and its landmarks still uncertain in a majority of general surgeons. The aim of this report is to propose a technical standardization and its anatomic concepts in the robotic-assisted eTEP ventral hernia repair. Methods: our group describes 10 key steps in a structured step-by-step approach for a safe and reproducible repair based on well defined anatomic landmarks, identification of zones of dissection and correct restoration of the linea alba. Results: the standardization has been developed 2 years ago and applied to all patients. A robotic-assisted surgery with 3 robotic arms is performed in a lateral docking setup. Feasibility is established and reproducibility is high among general surgeons. Conclusion: we present a standardized side docking robotic assisted ETEP approach for ventral hernia repairs with 10 key steps. We believe understanding the landmarks and a step-by-step guidance based on the concepts of retromuscular abdominal wall anatomy foment a safe learning of minimally invasive restoration of the abdominal wall integrity regarding non-expert surgeons.
\end{abstract}

Keywords: Hernia. Robotic Surgical Procedures. Rectus Abdominis. Abdomen. Postoperative Period.

\section{INTRODUCTION}

V entral hernias $(\mathrm{VH})$ are defects in the abdominal wall fascia. Their repairs are among the most commonly performed surgical procedures. Different surgical techniques for ventral hernia repair (VHR) have been described and, despite the high number of procedures, data to provide evidence and to establish best practices are scarce ${ }^{1}$. Conventional, open-approach corrections were based initially on closure of the primary defect, exhibiting higher recurrence rates compared with repairs with prostheses ${ }^{2}$. The laparoscopic VHR technique was first described 27 years ago and, with a similar rate of recurrence, shorter length of stay, and reduction in surgical site infection ${ }^{3,4}$. In 2012, Dr. Jorge Daes ${ }^{5}$ reported a new concept for exploring the extraperitoneal space, naming the technique "Enhanced Totally Extraperitoneal" (eTEP) in inguinal hernias, a notable innovation in the field of laparoscopic hernia surgery. The expanded operative field was added to the surgeons' arsenal in VHR, allowing better understanding of the retromuscular anatomy and greater familiarity with the minimally invasive extraperitoneal view of the abdominal wall from the posterior-anterior view. Overcoming some laparoscopic and ergonomics limitations, more recently, Beliansky et al. ${ }^{6}$ reported the use of a robotic platform in VHR, combining the use of the eTEP technique with the principles of releasing the transversus abdominis (TRA) muscle advocated by Novitsky et al. ${ }^{7}$. Favorable postoperative results and low recurrence rates have been encouraging ${ }^{8}$. To maintain the reliability and security of the robotic eTEP VHR, we

1 - Instituto Morrell, Cirurgia do Aparelho Digestivo Minimamente Invasiva e Robótica - São Paulo - SP - Brasil 2 - Sociedade Beneficente Israelita Brasileira Albert Einstein, Cirurgia Geral e do Aparelho Digestivo Minimamente Invasiva e Robótica - São Paulo - SP - Brasil 3 - Rede D'Or São Luiz, Cirurgia do Aparelho Digestivo e Robótica - São Paulo - SP - Brasil 
propose a standardized approach.

This article reports a standardization with systematic guidance of the robotics extended totally extraperitoneal ventral hernia repair (eTEP VHR) technique with lateral docking in 10 main stages, highlighting the anatomical landmarks of the retromuscular abdominal wall and the efficient surgical reconstruction of the linea alba.

\section{METHODS}

\section{The biomechanics of the abdominal wall}

The abdomen behaves like a hydraulic system with normal intra-abdominal pressure of about 5 to $7 \mathrm{mmHg}^{9}$. Restoration under physiological pressure of the linea alba should be the main objective of the ventral hernia repair, different than what was previously thought, i.e., only a tension-free correction.

\section{Anatomical landmarks}

Anatomically, the anterolateral abdominal wall is mainly formed by four symmetrical paired muscles. In addition to these four muscles (external oblique, internal oblique, transversus abdominis and rectus abdominis), the fascia transversalis and the parietal peritoneum are also important landmarks of the abdominal anatomy ${ }^{10}$.

The abdominal rectus muscle is involved in an aponeurotic sheath, consisting of the aponeurosis of the lateral abdominal muscles, completely involving its fibers anteriorly, and partially in its posterior aspect, above the arcuate line. At both lateral edges of the rectus muscle, there is a curved tendon intersection formed by the aponeurosis of the internal oblique, reinforced anteriorly by the external oblique and posteriorly by the transversus abdominis above the arcuate line, called linea semilunaris.

The arcuate line is the lower limit of the posterior layer of the rectus sheath, marking the transition from the retromuscular plane, which inferiorly consists only of the fascia transversalis and the parietal peritoneum. At this level, the lower epigastric vessels perforate the rectus abdominis. Near the linea semilunaris, at the junction between the posterior and anterior rectus sheaths, larger caliber neurovascular bundles (branches of the thoracoabdominal nerves) penetrate the lateral edge of the posterior rectus sheath.

\section{Preoperative evaluation}

Detailed, standardized, preoperative anamnesis and physical examination are compulsory. Also with respect to the hernia disease, type (primary or incisional), location in the abdominal wall (midline, lateral, lumbar), defect size, previous abdominal surgery, presence of single or multiple defects, loss of domain, or ostomies are important parameters when choosing the technique to be performed. We advocate imaging with Computed Tomography (CT) of the abdomen and pelvis to better assess the patient's anatomy and reliably measure the wall defect, evaluate the contents of the hernial sac, and measure the rectus muscle width. Patients with fistula or mesh infection may not be the best indication for the eTEP approach, unlike patients with midline hernias, multiple defects or a high body mass index (BMI), who have a greater likelihood of benefiting from the minimally invasive technique.

\section{Ten essential steps of standardized technique}

Step 1: Positioning the patient

All patients should be placed in the supine position, with arms closed along the trunk. For the greater distance between the costal margin and the antero-superior iliac crest, it is essential to flex the table, avoiding a possible external collision of the robotic arms. (Figure 1A). We encourage the insertion of a delayed bladder catheter to guarantee an empty bladder during the operation.

Step 2: Access to the retromuscular space and trocars placement

Although the placement of trocars, initially dynamically, was encouraged by Beliansky, the approach based on lateral docking ended up becoming the most versatile and reproducible configuration, suitable for most cases. The retromuscular access is performed near the left 
costal margin, with an incision above the projection of the rectus abdominis muscle, medial to the linea semilunaris. We use a $0^{\circ}$ or $30^{\circ} 5 \mathrm{~mm}$ laparoscopic camera with a 5 $\mathrm{mm}$ optical trocar to detach the sheath from the anterior rectum and reach the retromuscular space, taking care not to perforate the posterior fascia. Once the muscle fibers are identified, the insufflation of carbon dioxide (CO2) must be connected in high flow with a pressure of $15 \mathrm{mmHg}$. The diffusion of $\mathrm{CO} 2$ into the retromuscular space allows the safer entry of the trocar, which must be positioned slowly, penetrating this space parallel to the fibers of the rectus muscle, superficially the sheath, and in the craniocaudal direction. The blunt dissection is performed with the optics, to gain a wider access to the retromuscular space and sufficient visibility for placement of the remaining three robotic trocars. These trocars must be positioned as lateral as possible in the retromuscular plane, always medial to the linea semilunaris (Figure 1B). It is recommended an equidistant spacing of at least 78 $\mathrm{cm}$ between the robot portals to avoid external collision of its arms during surgery. It is also recommended that the lower $8 \mathrm{~mm}$ robotic trocar be not too close to the anterosuperior iliac crest, which can limit the movement of the robotic left arm, especially when working in the more cranial abdominal surgical field. A needle may be used to identify the correct location of the trocar when accessing the retromuscular space, thus avoiding its placement intraperitoneally, as well as injury to the linea semilunaris. Once the correct positioning of the portals is achieved, the robotic cart is approached for lateral docking on the patient's right side. One of the robotic arms kept aside and the remaining three are attached to the $30^{\circ}$ optics and the instruments. When using the da Vinci Xi platform (Intuitive Surgical Inc Sunnyvale, CA, USA), the optics must first be aimed at the target anatomy, in order to ensure the most appropriate configuration of the arms. Monopolar scissors and fenestrated bipolar forceps are placed on the right and left arms, respectively, with concomitant use of the needle holder during the procedure in the following steps. The $30^{\circ}$ endoscope should initially be pointing upwards towards the abdominal wall.

Step 3: Ipsilateral retromuscular dissection

Once the instruments and the optics are properly positioned, the first goal in the third step is to get an ample ipsilateral retromuscular space, ensuring a broad and ideal workspace. The medial border of the rectum must be exposed along the cranio-caudal length. The epigastric vessels and muscle fibers are exposed above, and the posterior sheath and the fascia transversalis below, respectively cranial and caudal to the arcuate line (Figure 2A and 2B).

Step 4: Crossover maneuver and reduction of hernia content

The crossover maneuver, described by Beliansky et al. ${ }^{6}$, represents the surgical dissection that joins the ipsilateral retromuscular space to the contralateral one without violating the intra-abdominal cavity. This is achieved first with an incision in the medial border of the posterior rectus sheath, allowing access to the preperitoneal space. (Figure $2 \mathrm{C}$ and 2D). The incisions should be made at a distance of approximately $1 \mathrm{~cm}$ from the linea alba to avoid injuries and to facilitate the visualization of the ipsilateral aponeurotic tissue during the suture and restoration of the anterior abdominal wall. The scissors should be used first in cold cuts to avoid thermal damage to possible intestinal contents inside the hernial sac and, once there is a good visualization of the preperitoneal space, monopolar energy can be applied. Before entering completely in the preperitoneal space and beginning the contralateral dissection, one should completely open the ipsilateral posterior rectus sheath, extending cranially from the subxiphoid region to the lower portion of the fascia transversalis caudally. The preperitoneal fat should be reduced as the dissection progresses, always moving superficially to the falciform and umbilical ligaments (Figure $3 \mathrm{~A}$ and $3 \mathrm{~B}$ ). Dissection of the area containing the aponeurotic defect to release the hernial sac is usually the most challenging phase of this fourth stage, due to tissue adherence and concerns about intestinal injuries. For this reason, it is highly recommended the dissection starts where the tissue has not yet been distorted. In some cases in which the peritoneum is too thin, adherent and there is not much preperitoneal fat, entry into the abdominal cavity may occur. An opening in the peritoneum produces intracavitary pneumoperitoneum, which can help release structures from the hernial sac. In addition, structures can be seen through intracavitary vision and precautions 
must be taken against any adherence found. Whenever possible, the reduction of the hernial sac is encouraged as much as possible, as this can be useful during the closure of the posterior layer for a tension-free suture.
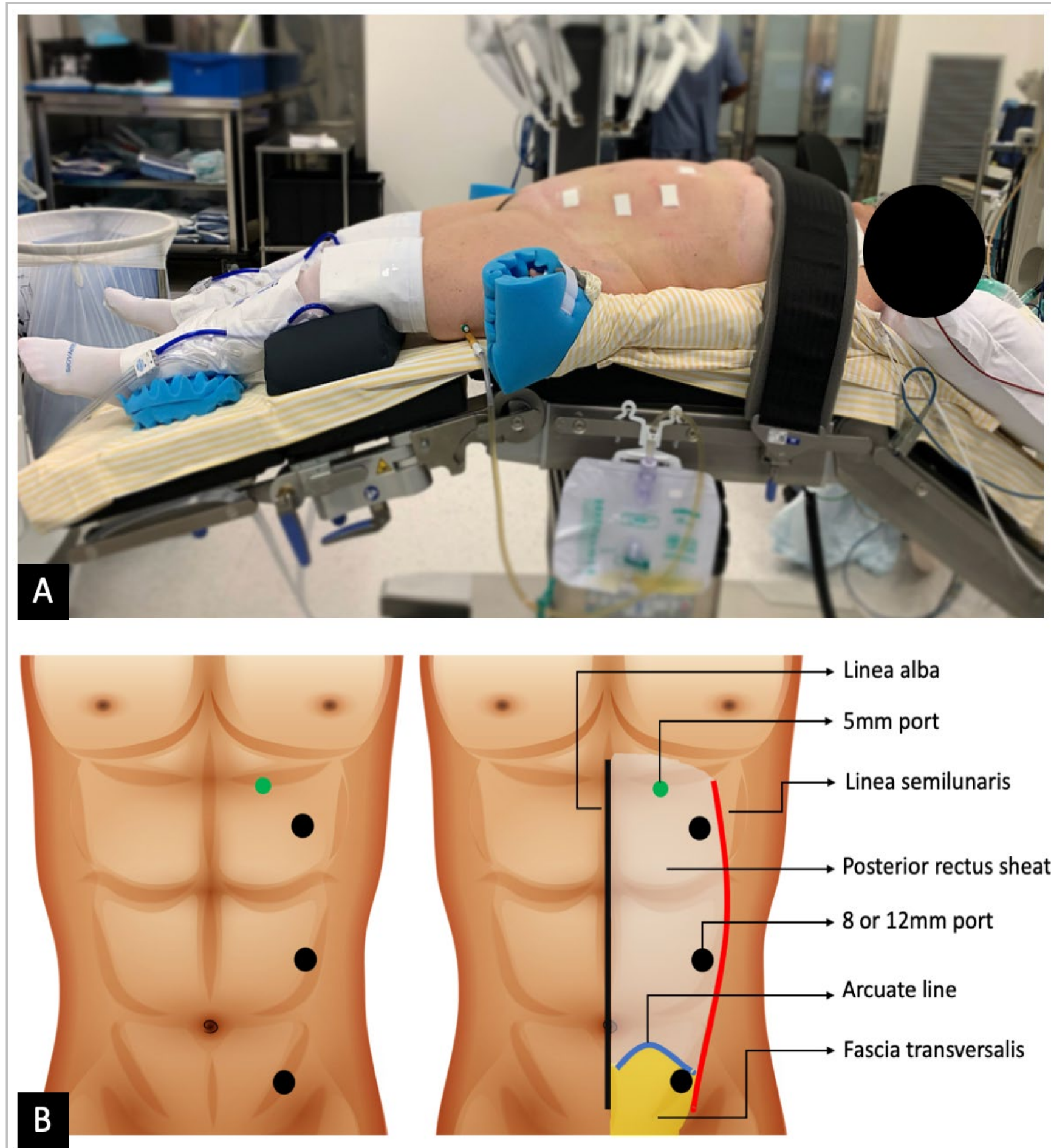

Figure 1. 1A: Flexing patient positioning with an increased distance between the border of the ribs and the anterior-posterior iliac spine. 1B: Anterior abdominal wall with the anatomic sites and the retromuscular trocars.

Step 5: Contralateral retromuscular dissection

Once the dissection and complete reduction of the hernial sac is performed and the preperitoneal fat is reduced, the fifth stage begins by incising the contralateral posterior sheath of the rectum $1 \mathrm{~cm}$ away 
from the linea alba (Figure $3 \mathrm{C}$ ). The same dissection made on the ipsilateral side then takes place. The fascia transversalis and the rectum posterior sheath should be fully open to access to the broad retromuscular contralateral space. At this point, positioning of the $30^{\circ}$ optics downwards allows better visualization of structures and delicate dissection to avoid injuries in neurovascular bundles. The muscle fibers of the rectum and epigastric vessels must always be placed superiorly as well as the areolar adipose tissue, while the fascia must be pulled downwards in order to provide counter-traction. When progressing laterally, major neurovascular bundles are important anatomical landmarks, demonstrating the proximity of the linea semilunaris and indicating the lateral dissection limit (Figure 3D). At this point, the three spaces (ipsilateral retromuscular, preperitoneal and contralateral retromuscular) previously partitioned, are now connected, forming a single, large, preperitoneal retromuscular plane.
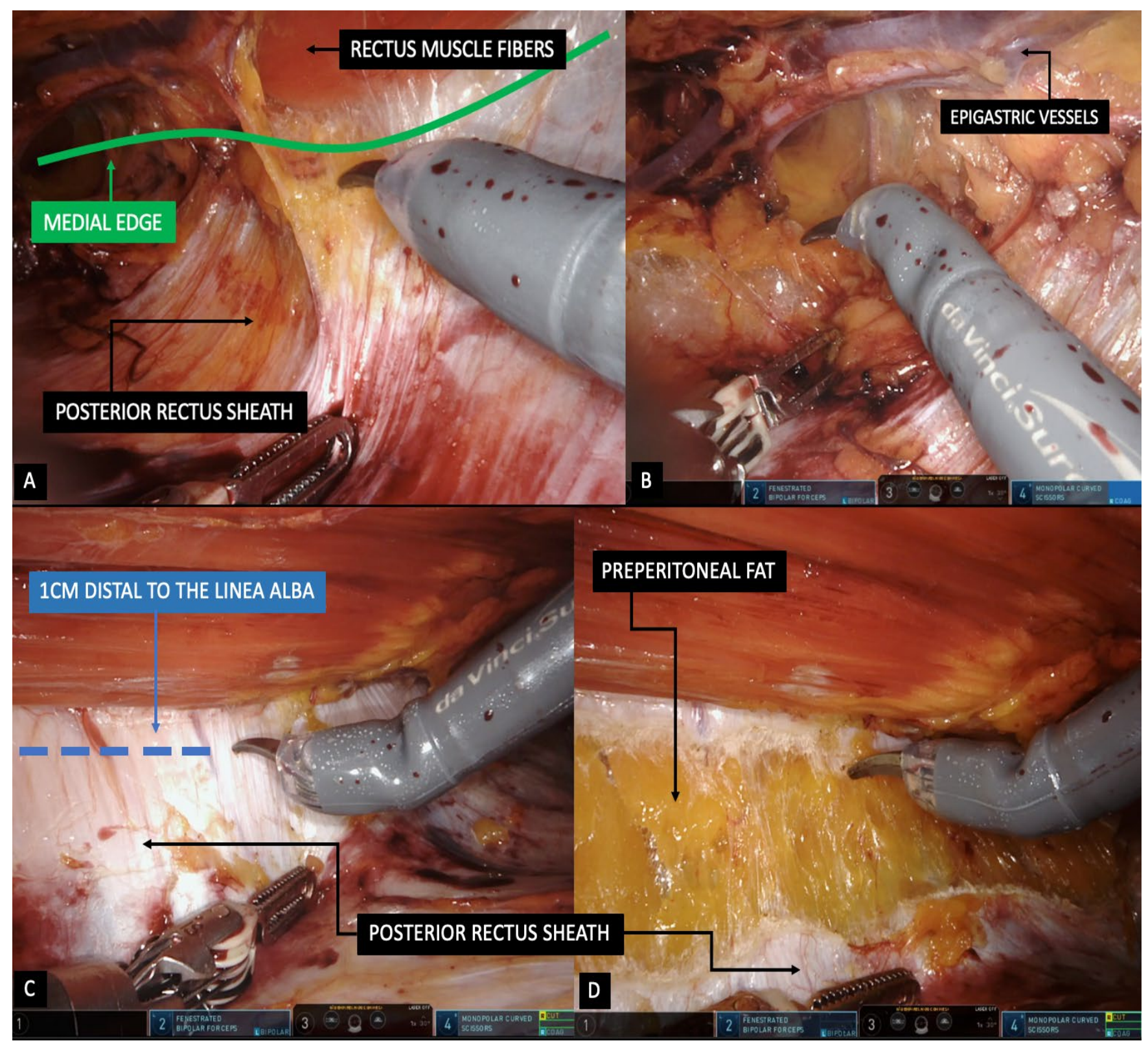

Figure 2. 2A: Retromuscular space showing the posterior sheath of the rectus and the medial border of the aponeurosis. 2B: Epigastric vessels above the dissection. 2C: Visualisation of the projection of the incision over the posterior rectus abdominis muscle, in order to start the crossover, at a $1 \mathrm{~cm}$ distance of the linea alba. 2D: Posterior opening of the fascia showing the pre-peritoneal fat. 


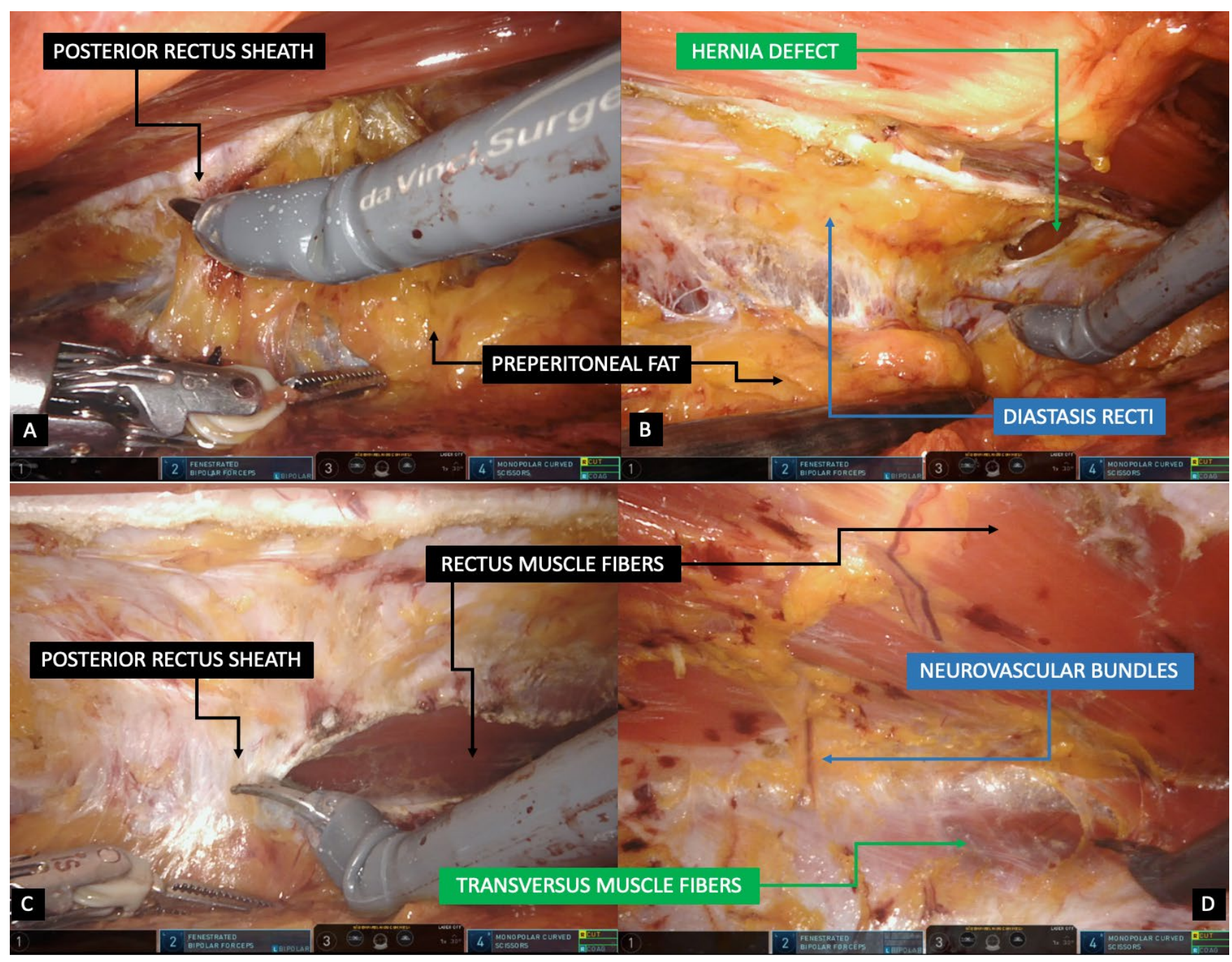

Figure 3. 3A: Dissection and opening of the inferior abdominal posterior fascia. 3B: Complete exposure of the anterior wall where it can be seen the hernial defect and the abdominal diastasis. 3C: Contralateral dissection by opening the posterior rectus abdominis sheath. 3D: Progression until the lateral border with the visualisation of the neurovascular bundles.

Stage 6: Wide craniocaudal extension of the retromuscular space

After reaching the lateral dissection limit, the retromuscular space must be completely exposed in the subxiphoid topography, always with caution not to injure the linea alba, and the caudal dissection must be concluded with the release of the umbilical ligament (Figure 4C and 4D). If inguinal hernias are also present, the bilateral exposure of the myopectineal orifice can also be performed to reduce hernia content and cover the defect with a local prosthesis.

Stage 7: TRA - transversus abdominis release

The approach to releasing the transversus abdominis muscle should always be considered when approaching the posterior fascia is not possible in a tension-free setting, sometimes due to a large defect or unwanted loss of peritoneal tissue or hernial sac. Familiarity with the TRA technique first described by Novitsky et al. ${ }^{11}$ is essential in the arsenal of surgeons who perform major reconstructions of the abdominal wall. Through the incision of the posterior lamella of the internal oblique in the upper third of the abdomen, the muscle fibers are exposed and sectioned to create the space between the transversalis fascia and the divided transversus abdominis muscle. The dissection continues with the release rate muscle caudally and, laterally, always avoiding opening the fascia transversalis. Special attention should be given to the dissection subxiphoid step, leaving the muscle fibers of the diaphragm always on the top field and the fascia transversalis downwards, avoiding 
the inadvertent creation of a Morgagni hernia. Bilateral TRA can be performed if necessary. A bottom up TRA is also possible, however, the lack of muscle fibers in the lower third of the transversus abdominis muscle can cause inexperienced surgeons to misinterpret the posterior lamella of the internal oblique and the peritoneum.

Stage 8: Reconstruction of the posterior fascia

If the extended totally extraperitoneal dissection has been performed, the posterior layer remained intact, with no need for closure. However, holes or small openings in the peritoneum often occur, and defects in the posterior layer must be closed (Figure 4A and 4B). The approximation of the fascia should be tensionfree due to the risk of early tissue rupture and possible intraparietal hernia. The use of barbed suture allows the closure without complications, preventing contact between the prosthesis and the abdominal viscera. Whenever necessary, the hernial sac can be used as a tissue extension for proper approximation. In this surgical step, the decrease in the pneumoperitoneum pressure to $8 \mathrm{mmHg}$ may make it easier to approximate the fascial borders, due to lower intracavitary tension.

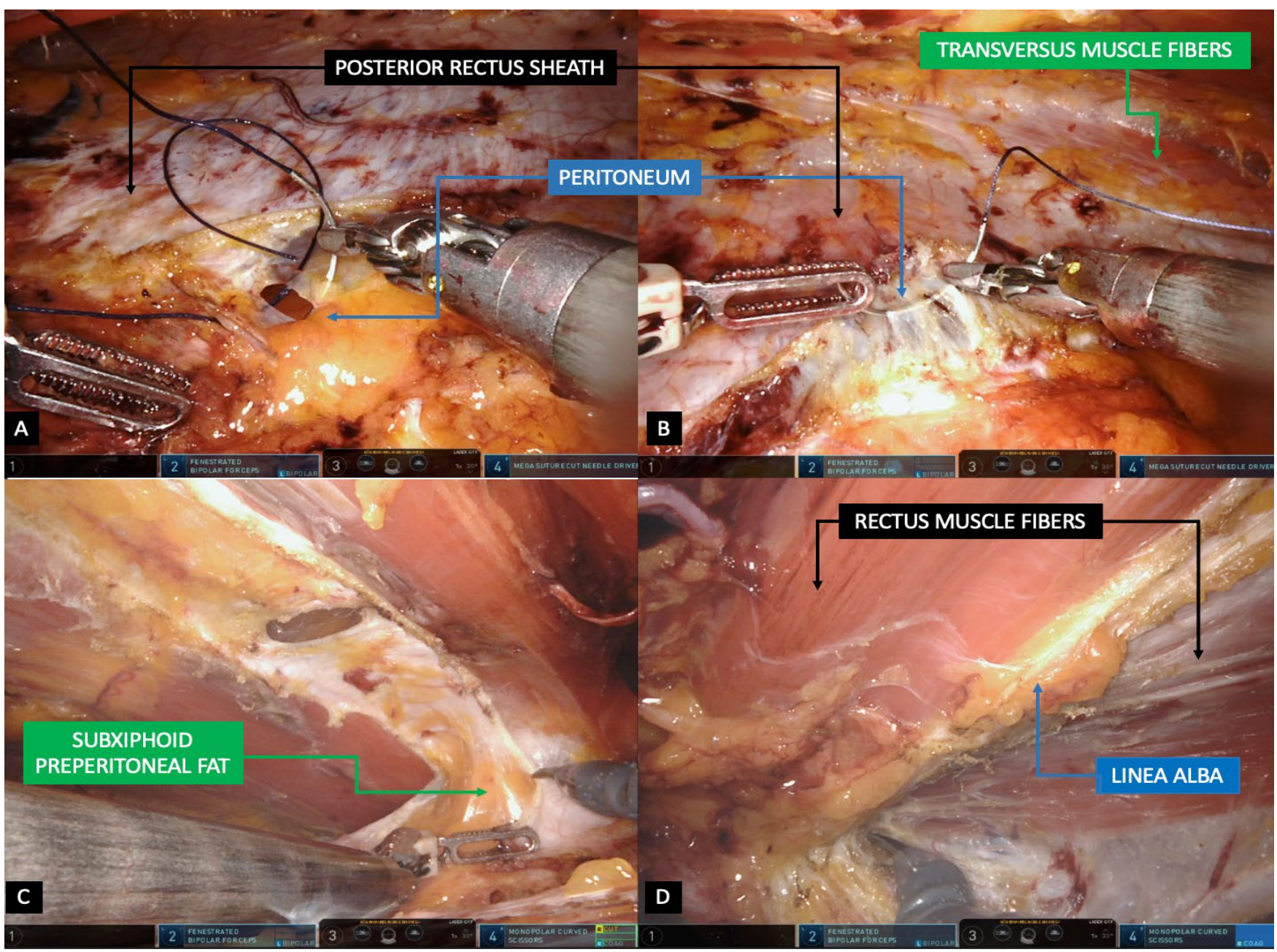

Figure 4. $4 A$ e $4 B$ : Closure of the posterior fascia due to inadvertent opening. $4 C$ and $4 D$ : Complete exposure of the retromuscular space with craniocaudal extension.

Step 9: Restoration of the anterior abdominal wall and of the linea alba

Once the posterior fascial layer is repaired, the next surgical step is to restore the midline. The $30^{\circ}$ optics must then face upwards, providing the ideal visualization of the defect size and of the ipsi and contralateral edges. Not infrequently, there is rectus abdominis muscle diastasis and the edges should also be approximated, concurrently with the defect closure (Figure 5A and 5B). If using the da 
Vinci Xi robotic platform, the image inversion maneuver can be extremely valuable, helping even more in the ergonomics and suturing of the anterior abdominal wall. This view is created by the maneuvers sequence both in the robotic console and in the instruments. In the robotic car next to the patient, one must reverse the instruments so they will be in a configuration opposite to the original one, followed by the reversal of the optics by $180^{\circ}$. Then, in the robotic console where the surgeon is seated, the instruments must be reassigned to the opposite hands, the command is confirmed, and the $30^{\circ}$ optics, moved in the opposite direction. This way, the suture that would be anteriorly held in the superior aspect of the surgical field is converted to a suture in the inferior field, of greater familiarity in minimally invasive procedures (Figure $5 \mathrm{C}$ and 5D). If not yet set, in this step it is also recommended the reduction of the $\mathrm{CO} 2$ pressure and the use of multiple barbed sutures along the defect, progressively promoting tension at the edges, thus avoiding tissue rupture when there are larger defects.

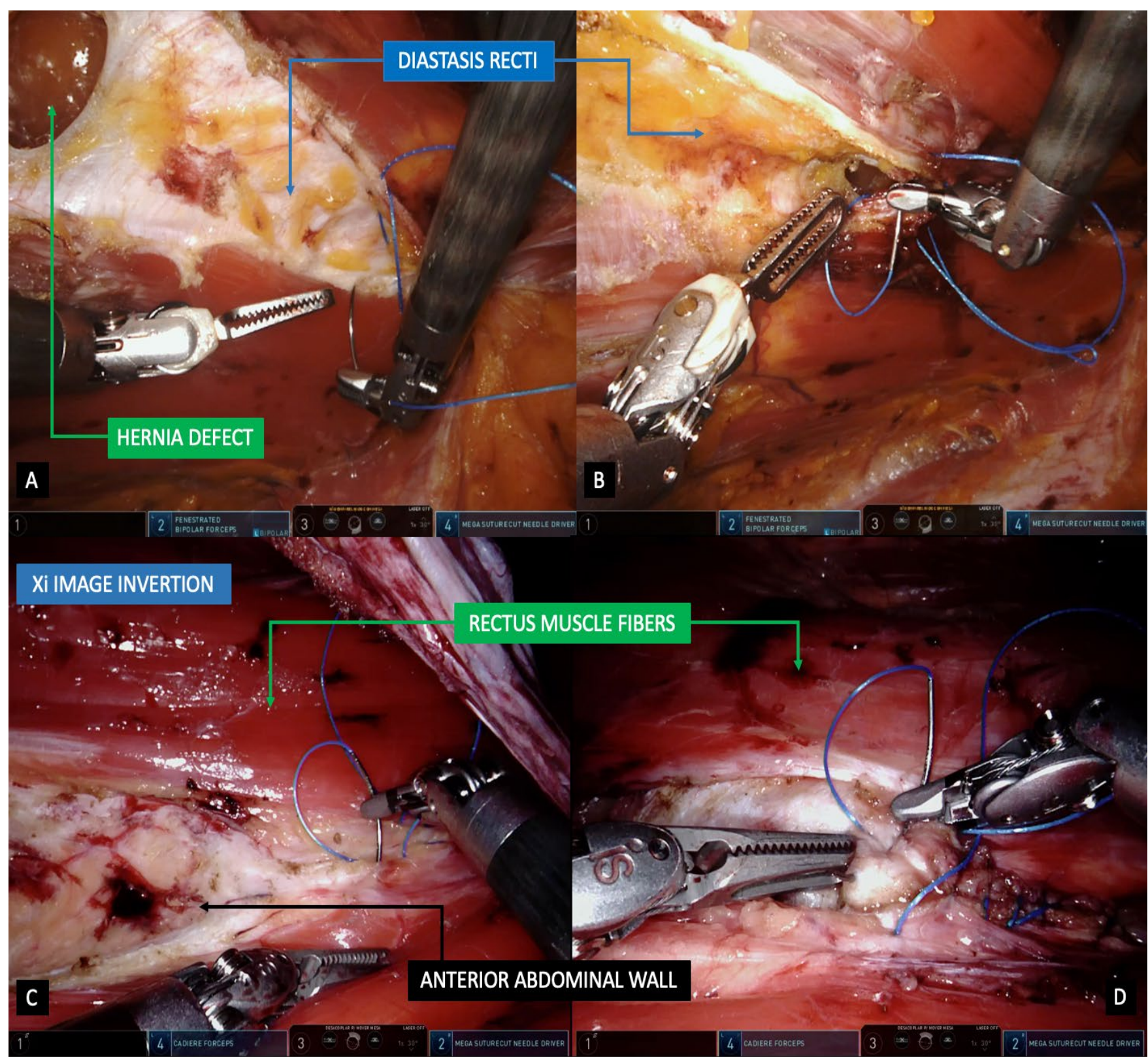

Figure 5. 5A: Rectus abdominis muscle borders and abdominal diastasis approximation. 5B: Repair of the hernial defect. 5C and 5D: Inversion of the images, promoting the suture of the anterior abdominal wall with the surgeon having an inferior horizon. 
Step 10: Positioning of the prosthesis

The prosthesis must be customized and introduced after measuring the dissected preperitoneal space and due coverage of the posterior fascia on which it will rest. The release of one of the robotic portals allows the insertion of the mesh, which is thus positioned on the posterior layer (Figure 6). Progressive $\mathrm{CO} 2$ deflation from the preperitoneal space takes place and the robotic trocars are removed under direct vision. There is no need for closure of the aponeurosis at the portal sites due to the intrinsic coverage of the area by the prosthesis.

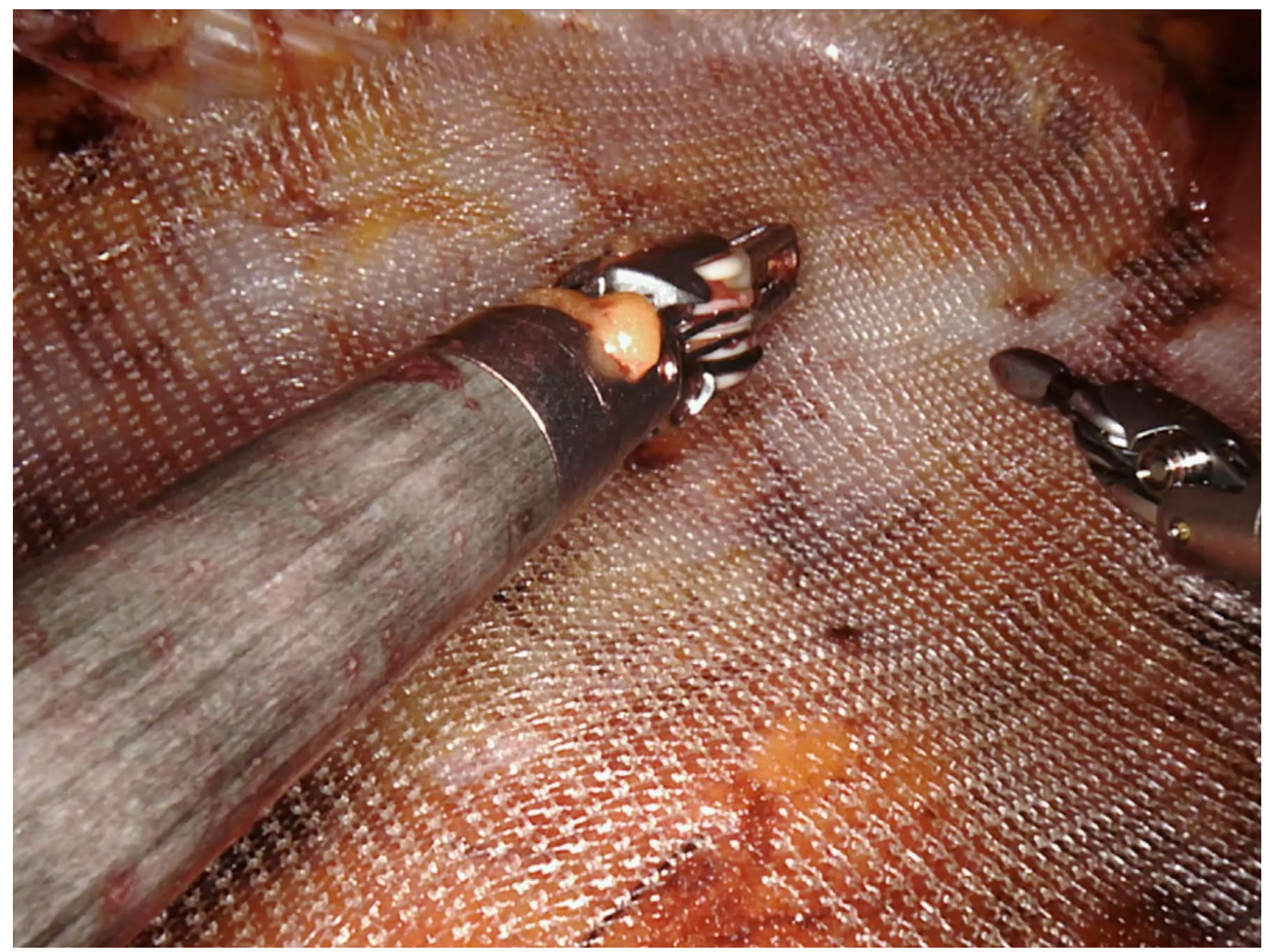

Figure 6. Hermetical prothesis positioning on the posterior fascia with no folds.

\section{RESULTS}

The standardized technique has been used by a group of surgeons whose series is one of the largest in Brazil, to our knowledge. In the period from June 2018 to February 2020, 22 patients underwent this standardized robotic extended totally extraperitoneal repair of ventral hernias. Twelve patients were female (54.4\%) and the average age was 49.7 years (range 3563), with an average BMI of $29.8 \mathrm{~kg} / \mathrm{m}^{2}$ (range 24.1
- 34.0). Surgical indications were all due to abdominal ventral hernias, with $8(36.4 \%)$ primary hernias and $14(63.6 \%)$ incisional defects. The average size of the largest defect dimension was $5.1 \mathrm{~cm}$ (range 3.5 - 11) and the average prosthesis coverage area was 433.5 $\mathrm{cm}^{2}$ (range 360 560). The lateral docking took place in all cases, 16 (72.8\%) of the procedures happening on a da Vinci Xi platform, while six (27.2\%) were performed on a Si technology. The average operative time on the console was $170.7 \mathrm{~min}$ (range 90 - 240). The restoration 
of the anterior abdominal wall and the linea alba, as well as the closure of the posterior layer, were achieved in all cases. There were no intraoperative complications, nor conversion to laparoscopy or open procedures. Most patients were discharged within 24 hours after the operation and there were no cases of mortality within 30 days. One patient was diagnosed with a minimal postoperative seroma and had complete recovery with conservative treatment. There was no recurrence in the series and the average follow-up period was 304.1 days (range 115 - 504).

\section{DISCUSSION}

Primary and incisional hernias are still common conditions that demand abdominal surgery. The concern with the open approach to ventral hernias remains with infections of wounds and prostheses. Approaches under the open technique of primary ventral hernias are associated with rates of surgical complications of up to $25 \%$, caused by surgical site infections (SSI), and recurrence rate in six months of up to $13 \%^{12}$. Even with the open retromuscular repair, which prevents the development of extensive subcutaneous flaps, the incidence of wound complications is not insignificant. Described for the first time by Leblanc et al. ${ }^{3}$, the feasibility of the laparoscopic VHR weakened the barrier of minimally invasive approach to ventral hernias, applied predominantly to the inguinal defects at the time. Intraperitoneal Onlay Mesh (IPOM), IPOM plus and other different types of prosthesis positioning were initially reported in the search for the ideal placement space $^{13}$. The Subcutaneous Onlay Laparoscopic Approach (SCOLA) with an extracavitary approach and fixation of a pre-aponeurotic mesh has also been described, but the rates of postoperative seroma due to dissection for adequate coverage of the overlap were not insignificant ${ }^{14}$. The benefits of the preperitoneal space in VHR have also been suggested over the years due to the obvious success of the Transabdominal Preperitoneal (TAPP) and Totally Extraperitoneal (TEP) approach for inguinal hernias.

In VHR, the retromuscular space offers some advantages in the reconstruction of complex abdominal wall defects. In addition to overcoming the limitations of intraperitoneal prostheses, avoiding adhesions, fistula, and migration, it provides ample potential space, which is easily dissected from the overlying muscle, providing a well vascularized compartment for both synthetic and biological meshes. In addition, the placement of the mesh on the retromuscular plane has been associated with more significant deposition of collagen types I and III when compared with the preaponeurotic placement ${ }^{15}$. Another important feature of the retromuscular space is that the posterior separation of the components can also be performed. In 2012, Novitsky et al. ${ }^{11}$ described the technique for releasing the transversus abdominis muscle, a technique for separating the posterior components with low perioperative morbidity and recurrence rates. When dissecting the space between the fascia transversalis and the division of the transversus abdominis muscle, the TRA procedure is reported to allow the placement of the prosthesis extending for approximately 6 to $8 \mathrm{~cm}$ from the midline on both sides, with greater medial advance of the posterior fascia and wider overlay. The purpose of performing TRA is to provide a closure of the posterior fascia in a tension-free scenario, sometimes difficult due to large defect or undesired loss of tissue or peritoneal hernial sac. Moreover, there is significant medial mobilization, avoiding the section of large neurovascular bundles of the anterolateral abdominal wall.

The experience of skilled surgeons to perform minimally invasive procedures allowed to explore the retromuscular space to repair ventral hernias using conventional laparoscopy. However, being not completely reproducible and insufficient in more complex cases or atypical defects with a great need for musculofascial dissection, the laparoscopic approach began to signal some limitations. The procedures assisted by robotics dramatically overcome the difficulties of dissection of the anterior abdominal wall, improving surgeons' ergonomics, dexterity and freedom of movement. In the era of robotic surgery, ventral hernia repairs combined with extended approach first described by Dr. Jorge Daes was disseminated by Belyansky et al. ${ }^{6}$, describing the first series of robotic VHR cases with the extended totally extraperitoneal technique (eTEP VHR). A comprehensive description of the results of 37 patients with complex hernia defects and different approaches with dynamic placement of trocars was analyzed, well accepted and encouraged by surgeons working in abdominal hernia operations. What was initially thought to be a positioning alternative, the 
lateral docking proved to be the most promising approach, with Kudsi and Gokcal ${ }^{16}$ also describing eTEP VHR assisted by robotics with lateral access.

Aiming at better reproducibility, teaching, and improving safety, some surgical anatomical landmarks and the main steps have also been reported in the literature. Strasberg et al. ${ }^{17,18}$ introduced the Critical View of Safety, known worldwide in laparoscopic cholecystectomy. Guidelines for uniform teaching and surgical learning can contribute to achieving high quality standards ${ }^{19}$. In the hernia scenario, Daes et al. ${ }^{20}$ reported nine main steps in the critical view of the myopectineal orifice in the laparoscopic repair of inguinal hernia, and Furtado et al. ${ }^{21}$ also reinforced the concept of the five triangles in the posterior view.

Some technical issues should be highlighted when learning the robotic eTEP VHR technique. Positioning the patient and correctly accessing the retromuscular space for placement of the trocars, performing the totally extraperitoneal crossover maneuver, and combining the three surgical spaces, in addition to not damaging the linea alba or the linea semilunaris and their respective larger neurovascular bundles, requires high familiarity with the posterior view of the anterior abdominal wall. The rationale of this study is to standardize and facilitate the concept of anatomy and the essential surgical steps for a safe robotic eTEP VHR. By emphasizing the anatomical landmarks and the dissection planes, the 10 essential steps of the standardized, systematic technique can prevent complications and improve patient care in cases performed by unskilled surgeons. Systematization was achieved after several cases, in what may be one of the most relevant series in Brazil to our knowledge, with safe and reproducible results.

\section{CONCLUSION}

The standardized approach, with ten essential steps in the robotics extended totally extraperitoneal ventral hernia repair (eTEP VHR) seeks high quality standards for the recently described technique, in a safe way. A systematic approach based on anatomical orientation can contribute to better understanding of the posterior view of the anterior abdominal wall and thus avoid unwanted complications by not yet experienced surgeons.

\title{
R E S U M O
}

\begin{abstract}
Objetivo: descritos pelo Dr. Jorge Daes, os princípios da visão aprimorada totalmente extraperitoneal (eTEP) têm mais recentemente sido utilizados no arsenal de reparos de hérnias ventrais. A realização da técnica de reparo totalmente extraperitoneal com o uso da robótica mostrou-se viável. No entanto, o verdadeiro conhecimento dos planos da parede abdominal retromuscular e os referenciais ainda são incertos para a maioria dos cirurgiões gerais. O objetivo deste artigo é propor padronização técnica e conceitos anatômicos no reparo de hérnia ventral robótico totalmente extraperitoneal (eTEP VHR). Métodos: nosso artigo descreve 10 etapas essenciais em abordagem estruturada passo a passo para procedimento seguro e reprodutível com base em referenciais anatômicos bem definidos, identificação de zonas de dissecção e restauração correta e completa da linha alba. Resultados: a padronização foi desenvolvida há 2 anos e aplicada a todos os pacientes. A cirurgia robótica é realizada com três braços da plataforma e por docking lateral. Conforme descrita, a reprodutibilidade e segurança são altas entre os cirurgiões gerais. Conclusão: apresentamos abordagem padronizada da técnica robótica de reparo de hérnia ventral totalmente extraperitoneal (eTEP VHR) em docking lateral por meio de 10 etapas essenciais. Acreditamos que a compreensão dos referenciais anatômicos e orientação passo a passo com base nos conceitos da anatomia do espaço retromuscular fomentam o aprendizado seguro, na atuação de cirurgiões não experientes durante a restauração minimamente invasiva da integridade da parede abdominal.
\end{abstract}

Palavras chave: Hérnia. Robótica. Reto do Abdome. Músculos Abdominais. Período Pós-Operatório.

\section{REFERENCES}

1. Helgstrand F. National results after ventral hernia repair. Dan Med J. 2016;63(7):B5258.

2. Mathes $T$, Walgenbach $M$, Siegel R. Suture Versus Mesh Repair in Primary and Incisional Ventral Hernias: A Systematic Review and Meta-Analysis. World J Surg. 2016;40(4):826-35.

3. LeBlanc KA, Booth WV. Laparoscopic repair of incisional abdominal hernias using expanded polytetrafluoroethylene: preliminary findings. Surg Laparosc Endosc. 1993;3(1):39-41.

4. Ramshaw BJ, Esartia P, Schwab J, Mason EM, Wilson RA, Duncan TD, et al. Comparison of laparoscopic and open ventral herniorrhaphy. Am Surg. 1999; 65(9):827-831.

5. Daes J. The enhanced view-totally extraperitoneal technique for repair of inguinal hernia. Surg 
Endosc. 2012;26(4):1187-9.

6. Belyansky I, Reza Zahiri H, Sanford Z, Weltz AS, Park A. Early operative outcomes of endoscopic (eTEP access) robotic-assisted retromuscular abdominal wall hernia repair. Hernia. 2018;22(5):837-47

7. Novitsky $\mathrm{YW}$, Fayezizadeh $\mathrm{M}$, Majumder A, Neupane R, Elliott HL, Orenstein SB. Outcomes of Posterior Component Separation With Transversus Abdominis Muscle Release and Synthetic Mesh Sublay Reinforcement. Ann Surg. 2016;264(2):22632.

8. Lu R, Addo A, Ewart Z, Broda A, Parlacoski S, Reza Zahiri $\mathrm{H}$, et al. Comparative review of outcomes: laparoscopic and robotic enhanced-view totally extraperitoneal (eTEP) access retrorectus repairs. Surg Endosc. 2020;34(8):3597-605. Epub 2019 Oct 11.

9. De Keulenaer BL, De Waele JJ, Powell B, Malbrain ML. What is normal intra-abdominal pressure and how is it affected by positioning, body mass and positive end-expiratory pressure? Intensive Care Med. 2009;35(6):969-76.

10. Coriddi M, Janis J. Tissue and fascial expansion of the abdominal wall. In: Rosen MJ. Atlas of Abdominal Wall Reconstruction. 2nd ed. Philadelphia, PA: Elsevier; 2015. p.185-201. Available from: http://www.us.elsevierhealth.com/ product. isbn=9781437727517\&navAction=\&navCount=0. Accessed 8 Oct 2015.

11. Novitsky YW, Elliott HL, Orenstein SB, Rosen MJ. Transversus abdominis muscle release: a novel approach to posterior component separation during complex abdominal wall reconstruction. Am J Surg. 2012;204(5):709-16.

12. Holihan JL, Alawadi Z, Martindale RG, Roth JS, Wray CJ, Ko TC, et al. Adverse events after ventral hernia repair: the vicious cycle of complications. J Am Coll Surg. 2015;221(2):478-85.

Received in: 20/05/2020

Accepted for publication: 19/06/2020

Conflict of interest: no.

Funding source: none.
13. Chelala E, Gaede F, Douillez V, Dessily M, Alle JL. The suturing concept for laparoscopic mesh fixation in ventral and incisional hernias: preliminary results. Hernia. 2003;7(4):191-6.

14. Claus CM, Malcher F, Cavazzola LT, Furtado M, Morrell A, Azevedo $M$, et al. Subcutaneous onlay laparoscopic approach (SCOLA) for ventral hernia and rectus abdominis diastasis repair: technical description and initial results. ABCD Arq Bras Cir Dig. 2018;31(4):e1399.

15. Binnebösel $M$, Klink CD, Otto J, Conze J, Jansen $\mathrm{PL}$, Anurov $\mathrm{M}$, et al. Impact of mesh positioning on foreign body reaction and collagenous ingrowth in a rabbit model of open incisional Hernia. 2010;14(1)71-7.

16. Kudsi OY, Gokcal F. Lateral approach totally extraperitoneal (TEP) robotic retromuscular ventral hernia repair. Hernia. 2019 Nov 27. Online ahead of print.

17. Strasberg SM, Hertl M, Soper NJ. An analysis of the problem of biliary injury during laparoscopic cholecystectomy. J Am Coll Surg. 1995;180(1):10125.

18. Strasberg SM, Brunt LM. Rationale and use of the critical view of safety in laparoscopic cholecystectomy. J Am Coll Surg. 2010;211(1):1328.

19. Dijkstra FA, Bosker RJ, Veeger NJ, van Det MJ, Pierie JP. Procedural key steps in laparoscopic colorectal surgery, consensus through Delphi methodology. Surg Endosc. 2015;29(9):2620-7

20. Daes J, Felix E. Critical view of myopectineal orifice. Ann Surg. 2017;266(1):e1-e2.

21. Furtado M, Claus CMP, Cavazzola LT, Malcher F, Bakonyi-Neto A, Saad-Hossne R. Systemization of laparoscopic inguinal hernia repair (TAPP) based on a new anatomical concept: inverted $Y$ and five triangles. Arq Bras Cir Dig. 2019;32(1):e1426.

\section{Mailing address:}

Andre Luiz Gioia Morrell

E-mail: andremorrell@gmail.com 